\title{
Enhancement of performance and biodegradability kinetics of aerobic-anaerobic sludge digestion
}

\author{
Boonchai Wichitsathian ${ }^{1, *}$, Jareeya Yimratanabovorn ${ }^{1}$ and Watcharapol Wonglertarak ${ }^{1}$ \\ ${ }^{1}$ School of Environmental Engineering, Institute of Engineering, Suranaree University of Technology, Nakhon Ratchasima, 30000 , \\ Thailand.
}

\begin{abstract}
The excess sludge problem from a wastewater treatment plant is a great concerned due to the high cost of sludge management accounting for about $20 \%$ to $50 \%$ of the total operating cost. Therefore, sludge reduction is critical. Currently, aerobic and/or anaerobic sludge digestions are widely used in the industries for treating the excess sludge. The objective of this research was to study the effects of aeration rate and temperature on the excess sludge reduction by using the aerobic-anaerobic digestion system in the laboratory. The aeration rates of $1.0,0.5$, and 0.1 volume air per volume slurry per minute (vvm) at the room temperature and the thermophilic temperature $\left(55 \pm 2^{\circ} \mathrm{C}\right)$ were investigated. The results showed that the highest removal efficiency of aerobic sludge digestion was obtained at the thermophilic temperature and aeration rate of $1.0 \mathrm{vvm}$. The removal efficiency of organic matter in terms of COD, total solids (TS) and volatile solids (VS) were $34.76 \%, 33.01 \%$ and $43.45 \%$, respectively. Consequently, the highest specific growth rate of microorganisms was 0.39 per hour and the substrate removal rate was 0.55 milligram

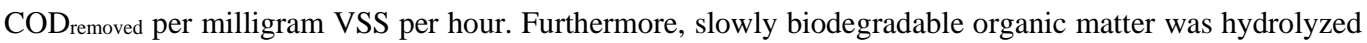
to readily biodegradable organic matter and inert soluble organic matter. When the sludge effluent from aerobic sludge digestion was feed to the anaerobic sludge digestion, the removal efficiency of organic matter in terms of COD, TS and VS were increased by $25 \%, 17 \%$ and $28 \%$, respectively. Moreover, the obtained methane production rate in the anaerobic sludge digestion was approximate $0.234 \mathrm{~m} 3 / \mathrm{kg}$ COD removed.
\end{abstract}

\section{Introduction}

The activated sludge process is the most widely used biological process for domestic wastewater treatment. During aerobic biological treatment, organic pollutants are mineralized into carbon dioxide and water with the generation of an excess bacterial biomass commonly known as a waste activated sludge. The treatment, handling and disposal of this excess sludge account for up to $60 \%$ of the total wastewater treatment plant operating costs [1]. The large amount of waste sludge, constituting of refractory and non-biodegradable cellulose compounds, leads to difficulty of sludge disposal [2]. Sludge stabilization is employed to deduct germs and prevent sludge decomposition. The process can be conducted by chemical processes such as lime stabilization, physical processes such as heat stabilization and ultrasound, and bio-organic processes such as composting, anaerobic digestion, and aerobic digestion. The aerobic digestion process is similar to the method of the activated sludge (AS), which aims at eliminating organic dust or volatile solid. Not only does the aerobic digestion stabilize sludge, but it also reduces the quantity of excess sludge from the process [3-5]. As a result, the dewatering process can be achieved more easily and the sludge decomposition is prevented [6].
Anaerobic digestion on the other hand, employs microorganisms in the decomposition of organic substance in an anaerobic digestion environment by transforming organic substance into methane $\left(\mathrm{CH}_{4}\right)$, carbon dioxide $\left(\mathrm{CO}_{2}\right)$, and water [3, 5]. However, numerous kinds of bacteria are needed. Each type of bacteria has its own function in the digestion process. Previous studies suggested that the anaerobic digestion at thermophilic temperature, $50-55^{\circ} \mathrm{C}$, reduces the solidification by $40-50 \%$ and lessens the dissolvable chemical oxygen demand (COD) by $20-30 \%$ during 10 15 days of the hydraulic retention time (HRT). When the digestion process was set at mesophilic temperature, $37^{\circ} \mathrm{C}$, the COD was proved to be reduced by $35 \%$ and $60 \%$ during 30 days and 20 days of the HRT, respectively [7-10]. On the other hand, the aerobic digestion sets at thermophilic temperature, $55^{\circ} \mathrm{C}$, reduces $33 \%$ of the solidification and eliminates $65 \%$ of the dissolvable COD within 15 hours. It also creates less volatile acid at this temperature. Apart from this, results of the studies suggested that higher level of aeration can effectively increase the level of decomposition [11-12]. With the intention to enhance the excess sludge reduction and increase the biodegradable, in this study, the processes of the aerobic-anaerobic digestions with a variation of the aeration rate and temperature were investigated. 


\section{Materials and method}

\subsection{Sludge samples}

In order to evaluate the continuous performance of the aerobic-anaerobic digestion system, the excess sludge collected from the wastewater treatment plant of an industry was preserved at the temperature $4{ }^{\circ} \mathrm{C}$ for an inhibition of the microorganism growth. The characteristics of the excess sludge are presented in Table 1 .

Table 1. Characteristic of excess sludge from activated sludge process.

\begin{tabular}{|l|c|}
\hline \multicolumn{1}{|c|}{ Parameter } & Value \\
\hline Total Solids, TS (mg/L) & $10,372 \pm 507$ \\
\hline Total Volatile Solids, TVS (mg/L) & $9,317 \pm 550$ \\
\hline Suspended Solids, SS (mg/L) & $9,699 \pm 622$ \\
\hline Volatile Suspended Solids, VSS (mg/L) & $8,693 \pm 647$ \\
\hline Total COD (mg/L) & $10,880 \pm 657$ \\
\hline Soluble COD (mg/L) & $530 \pm 56$ \\
\hline Total BOD (mg/L) & $2,174 \pm 626$ \\
\hline Soluble BOD (mg/L) & $544 \pm 92$ \\
\hline TBOD/TCOD & 0.27 \\
\hline VS/TS & 0.90 \\
\hline
\end{tabular}

\subsection{Experimental set-up}

The schematic diagram of the experimental set-up consisting of a sludge storage and aerobic-anaerobic digestion unit and the operating conditions are shown in Figure 1 and Table 2, respectively.

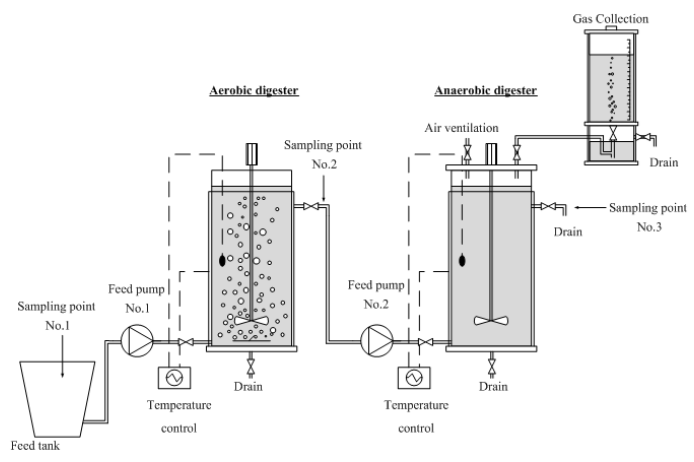

Fig. 1. Schematic diagram of the experimental set-up.

The effluent steam from the aerobic digestion reactor was transferred to the anaerobic digestion reactor. The working volume of both reactors was $10 \mathrm{~L}$. In the aerobic digestion reactor, the sludge was mixed by the diffused aeration system placed at the bottom of the reactor to maintain an aeration rate of $0.1,0.5$ and $1.0 \mathrm{vvm}$. (volume air per volume slurry per minute). The temperature was maintained at the ambient temperature for mesophilic condition and $55 \pm 2{ }^{\circ} \mathrm{C}$ for thermophilic condition.
Table 2. The operating conditions of the aerobic-anaerobic digestion processes.

\begin{tabular}{l|c:c}
\hline $\begin{array}{c}\text { Operating } \\
\text { conditions }\end{array}$ & $\begin{array}{c}\text { Aerobic } \\
\text { digestion (AeD) }\end{array}$ & $\begin{array}{c}\text { Anaerobic } \\
\text { digestion (AnD) }\end{array}$ \\
\hline $\mathrm{pH}$ & $6.8-7.2$ & - \\
Organic loading rate & $\begin{array}{c}1.0-1.125 \\
\mathrm{kgVSS} / \mathrm{m}^{3}-\mathrm{d}\end{array}$ & Effluent from AeD \\
\hline Temperature $\left({ }^{\mathrm{O}} \mathrm{C}\right)$ & $\begin{array}{c}\text { Ambient } \\
\text { and 55 }\end{array}$ & Ambient and $55 \pm 2$ \\
\hdashline Aeration rate $(\mathrm{vvm})$ & $0.1-1.0$ & - \\
\hline HRT (days) & 8 & 8 \\
\hline
\end{tabular}

\subsection{Kinetic evaluations}

The oxygen uptake rate (OUR) experiments were conducted to determine the biodegradability kinetic coefficients of the aerobic heterotrophs following the procedure conducted by [13]. The batch tests shown in Figure 2 were maintained at the temperature $30 \pm 0.5{ }^{\circ} \mathrm{C}$, $\mathrm{pH} 7 \pm 0.2$, and added the suppressing nitrification of 10 $\mathrm{mg} \mathrm{N}$-ammonia/L. The initial ratio of substrate to microorganism $\left(\mathrm{S}_{0} / \mathrm{X}_{0}\right)$ was about 1.0-2.0. Suspended solids (MLVSS) concentration $\left(\mathrm{X}_{0}\right)$ in the sludge samples was about $300 \mathrm{mg} / \mathrm{L}$ for the batch tests and the various substrate concentrations $\left(\mathrm{S}_{0}\right)$ that govern the quality of the batch respirometric tests. The OUR results were used for calculating the maximum specific growth rates $\left(\mu_{\max }\right)$, substrate utilization rate $\left(\mathrm{r}_{\mathrm{x}}\right)$, half-velocity constant $\left(\mathrm{K}_{\mathrm{S}}\right)$, and sludge yield coefficient $(\mathrm{Y})$ based on Monod kinetics by regression analysis.

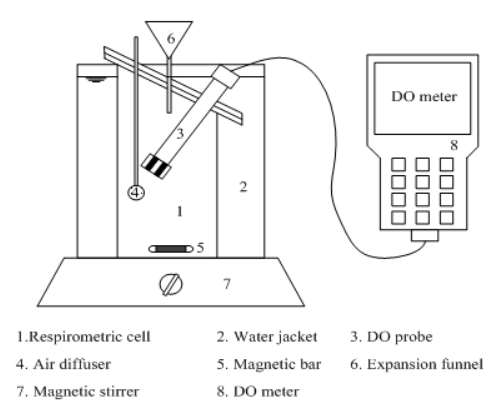

Fig. 2. Respirometer: 1) Respiration cell, 2) Water jacket, 3) Air diffuser, 4) DO probe, 5) Magnetic bar, 6) Magnetic stirrer, 7) Expansion funnel, 8) DO meter, and 9) Water bath.

\subsection{Analytical methods}

The influent and effluent samples were analyzed for total solids (TS), total volatile solids (TVS), suspended solids (SS), volatile suspended solids (VSS), total chemical oxygen demand (total COD) and soluble chemical oxygen demand (soluble COD) following the Standard Methods for the examination of water and wastewater, and [14]. The carbonaceous material characterizations were measured in terms of the COD parameter subdivided into a number of fractions following [15] 


\section{Results and discussion}

\subsection{Effects of aeration rate and temperature in aerobic digestion}

A primary sludge treatment process is required to increase the proportion of easily degradable organic material in the process. A further address in this research was the observation of the influence of temperature and aerating rate on the common processes of the aerobic and anaerobic degradation. It can be drawn from the study that, in the aerated degradation process, the solid reduction and COD removal in the forms of TS, VS, and COD were found to be $28.20 \%, 35.76 \%$, and $30.46 \%$, respectively, for the aerating rate of $1.0 \mathrm{vvm}$ at the mesophilic temperature (AeM1). For the aerating rate of $0.5 \mathrm{vvm}(\mathrm{AeM} 2)$, it was found to be $24.83 \%, 35.76 \%$, and $27.05 \%$ for TS, VS, and COD, respectively. The reduction efficiency was obtained around $19.53 \%$, $25.01 \%$, and $20.50 \%$ for TS, VS, and COD, respectively, when the aerating rate of $0.1 \mathrm{vvm}(\mathrm{AeM} 3)$ was applied, as shown in Figure 3. Nevertheless, when using the statistical t-test with the $95 \%$ confidence, it turned out that the aerobic degradation processes at the mesophilic temperature with the studied variation of aerating rates did not have a statistical significant difference in terms of the solid reduction efficiency.

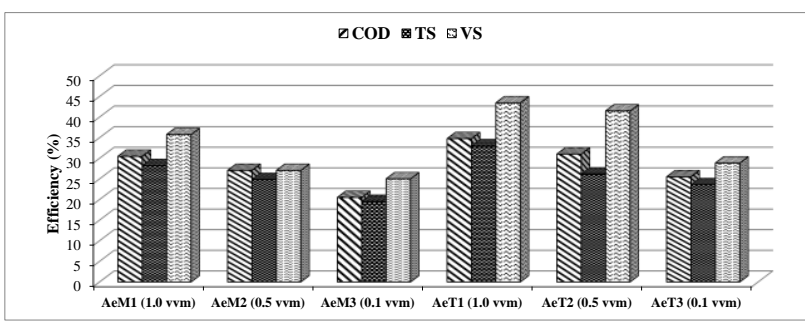

Fig. 3. Variations of efficiency remove organic matter on aerobic digestion.

For the aerobic digestion process at the thermophilic temperature, the reduction efficiencies of TS, VS, and COD were $33.01 \%, 43.45 \%$, and $34.76 \%$, respectively, with the aerating rate of 1.0 (AeT1). It has proved to perform better compared to those with the aerating rates of $0.5 \mathrm{vvm}(\mathrm{AeT} 2)$ and $0.1 \mathrm{vvm}(\mathrm{AeT} 3)$ [11]. However, the solid reduction efficiencies were not significantly different for the introduced aerating rates at the thermophilic temperature when testing with the statistical t-test at the $95 \%$ confidence. Noticeably, the average solid removal efficiency at the thermophilic temperature was slightly higher than that at the mesophilic one.

Higher removal efficiency of organic matter in terms of TS, VS, and COD was obtained at higher aeration rates $(1.0$ and $0.5 \mathrm{vvm})$ because they provide sufficient dissolved oxygen for the aerobic bacteria to use for converting the hydrolysable substrate to readily biodegradable substrate, for the uptake growth of the biomass, and for maintenance purposes.

\subsection{Efficiency in the aerobic-anaerobic digestion processes}

The average organic matter reduction efficiency at the thermophilic temperature is higher than that at mesophilic for the organic matter removal of the excess sludge using the common aerobic and anaerobic degradation process. Under the studied conditions, approximate $35-50 \%$ solid reduction at 16 days HRT- 8 days aerobic exposure and 8 days anaerobic exposure. The aerating rate of $1.0 \mathrm{vvm}$ at the mesophilic temperature in aerobic digestion (AeM1) and anaerobic digestion (AnM1) yielded the removal efficiency of $41.45 \%, 50.81 \%$ and $45.08 \%$ for TS, VS and COD, respectively. The aerating rate of $0.5 \mathrm{vvm}$ condition in aerobic digestion (AeM2) and anaerobic digestion (AnM2) resulted in the reduction efficiency of $34.42 \%, 48.81 \%$ and $37.02 \%$ for TS, VS and COD, respectively. The thermophilic aerobic digestion (AeT1) and anaerobic digestion (AnT1) with the aerating rate of $1.0 \mathrm{vvm}$ produced the removal efficiency of $50.40 \%$, $71.28 \%$ and $59.49 \%$ for TS, VS and COD, respectively, while the thermophilic aerobic digestion (AeT2) and anaerobic digestion (AnT2) with the aerating rate of 0.5 vvm removed $28.35 \%, 61.82 \%$ and $49.23 \%$ for TS, VS and $\mathrm{COD}$, respectively.

With the incorporation of the anaerobic process, the solid reduction efficiency at the thermophilic temperature was found to be in the range of $13-15 \%$ while falling between $10-13 \%$ at the mesophilic temperature, as shown in Figure 4. It was further found that the efficiency of reducing easily vaporized sludge varied with the change of temperature and aerating rate $[7-8,10,16]$. When applying the statistical t-test at the $95 \%$ confidence, the anaerobic degradation processes at the thermophilic temperature showed the significant difference in terms of solid reduction efficiency.

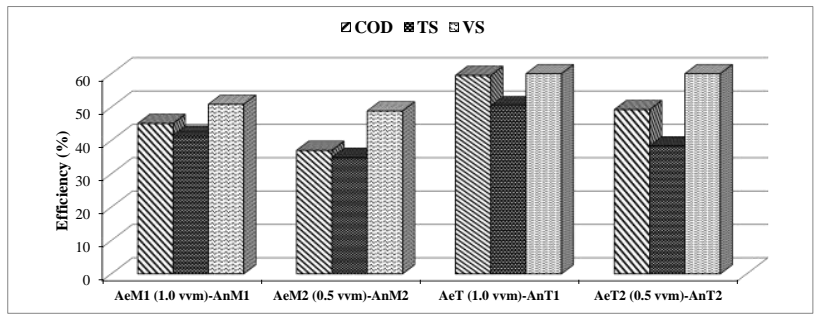

Fig. 4. Average efficiency in aerobic-anaerobic digestion process at mesophilic and thermophilic temperature.

Gas production shown in Table 3 was $0.062,0.058$, 0.211 and $0.156 \mathrm{~L} / \mathrm{d}$ for AnM1, AnM2, AnT1 and AnT2, respectively at a gas production rate $0.009-0.046 \mathrm{~m}^{3} / \mathrm{kg}$ $\mathrm{VS}_{\text {fed. }}$ The thermophilic temperature condition increased the gas production because it is suitable to hydrolyze much organic matter into the soluble forms that could immediately be. These conditions could make the organic matter release from the inner fractions to the outer fractions, thus increasing the hydrolysis rate of granular organics and improving the digestion efficiency [11-12]. For the effect of temperature on the anaerobic digestion, it was found that the thermophilic anaerobic digestion was much faster than the mesophilic anaerobic digestion. In thermophilic anaerobic digestion, the waste activated 
sludge had the thermal lysis of microbial cell as the dominant mechanism, resulting in the high degradation rate. References [17] showed that the performance of the reactor could be improved with the increase in temperature and HRT 20 days. The COD removal increased from $35 \%$ in the mesophilic condition to $45 \%$ in thermophilic, the gas production were 0.33 and 0.45 $\mathrm{m}^{3} / \mathrm{kg} \mathrm{VS}_{\text {fed }}$ at the mesophilic and thermophilic conditions, respectively.

Table 3. Variations of gas production on anaerobic condition

\begin{tabular}{|c|c|c|c|c|}
\hline Condition & AnM1 & AnM2 & AnT1 & AnT2 \\
\hline $\begin{array}{l}\text { Gas production } \\
\text { (L/day) }\end{array}$ & $0.062 \pm 0.011$ & $0.058 \pm 0.011$ & $0.211 \pm 0.059$ & $0.156 \pm 0.047$ \\
\hline \multicolumn{5}{|l|}{$\begin{array}{l}\text { Gas production } \\
\text { rate }\end{array}$} \\
\hline $\begin{array}{c}\mathrm{m}^{3} / \mathrm{kg} \text { VS } \\
\text { remove }\end{array}$ & $0.174 \pm 0.049$ & $0.163 \pm 0.038$ & $0.254 \pm 0.073$ & $0.243 \pm 0.066$ \\
\hline$-\mathrm{m}^{3} / \mathrm{kg} \mathrm{COD}$ & $0.060 \pm 0.006$ & $0.058 \pm 0.006$ & $0.234 \pm 0.074$ & $0.221 \pm 0.094$ \\
\hline$-\mathrm{m}^{3} / \mathrm{kg} \mathrm{VS}$ fed & $0.009 \pm 0.002$ & $0.008 \pm 0.002$ & $0.063 \pm 0.015$ & $0.046 \pm 0.014$ \\
\hline $\begin{array}{c}-\mathrm{m}^{3} / \mathrm{kg} \text { COD } \\
\text { fed }\end{array}$ & $0.006 \pm 0.001$ & $0.006 \pm 0.001$ & $0.044 \pm 0.013$ & $0.043 \pm 0.012$ \\
\hline
\end{tabular}

\subsection{COD fractionation and biodegradability kinetics}

COD fractionations were evaluated for the potential biodegradability and the results are illustrated in Fig 5 . The result showed that the slowly biodegradable organic matter was hydrolyzed to the readily biodegradable organic matter and inert soluble organic matter. Readily biodegradable organic substrate $\left(\mathrm{S}_{\mathrm{s}}\right)$ decreased at diferent aerating rates and tempertures. Slowly biodegradable organic substrate $\left(\mathrm{X}_{\mathrm{S}}\right)$ and inert soluble organic matter $\left(\mathrm{S}_{\mathrm{I}}\right)$ had the maximum value at the aerating rate of $1.0 \mathrm{vvm}$. The inert particle organic matter $\left(\mathrm{X}_{\mathrm{I}}\right)$ had the minimum value at the aerating rate of $1.0 \mathrm{vvm}$. This showed that the hydrolysis from $X_{S}$ into $S_{S}$ and $S_{I}$ occurred more at the higher aerating rate, and the removal of organic matter was also more efficient at the higher aerating rate. With the observation of TS, VS, and COD removal efficiency at the aerating rate of $1.0 \mathrm{vvm}$, at the thermophilic temperature condition, $X_{I}$ reduced by the ratio of the rate of the hydrolysis and biodegradable was higher than that at the mesophilic temperature.

The biodegradability kinetics of the microbial aerobic digestion at the thermophilic and mesophilic condition with the aerating rate 1.00 .5 and $0.1 \mathrm{vvm}$ is shown in Table 4. As the result, the highest specific growth rate of microorganisms was 0.39 per hour and the substrate removal rate was 0.55 milligram COD removed per milligram VSS per hour. It showed that the $\mu_{\max }$ and $\mathrm{R}_{\mathrm{X}}$ was higher when increasing the aeration rate. However, the aeration rate of 1.0 and $0.5 \mathrm{vvm}$ provided no significant difference in the rates of the microbial growth and substrate removal. As a result, the ratio of increases substrate due to the growth of microorganisms increases, to uptake substrate that removed easily biodegradable. This is consistent with the removal efficiency of organic matter in terms of COD, TS and VS. When the $\mu \max$ and $\mathrm{R}_{\mathrm{X}}$ on the thermophilic and mesophilic conditions were compared, the thermophilic $\mu \max _{\max }$ and $\mathrm{R}_{\mathrm{X}}$ were found to be greater than the mesophilic ones. This showed that the temperature importantly effects the specific growth rate. At the same aerating rate, higher temperature results in a well growth of microbes. According to $\mathrm{k}_{\mathrm{d}}$, it showed that the death rates increased when the aerating rate decreased.

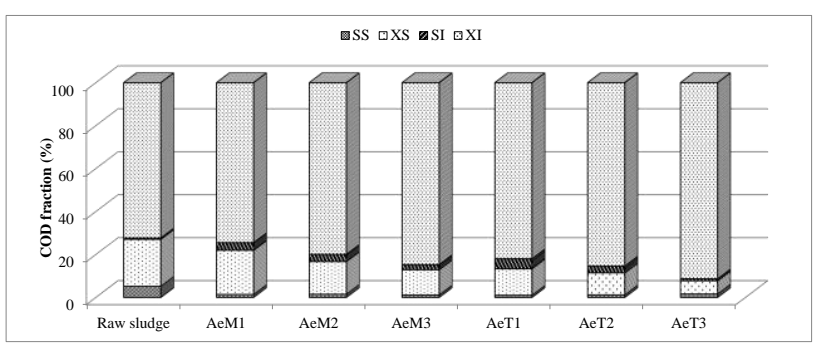

Fig. 5. COD fraction on aerobic digestion

Table 4. Biodegradability Kinetic on aerobic digestion

\begin{tabular}{|c|c|c|c|c|c|c|}
\hline \multirow{2}{*}{ Parameter } & \multicolumn{3}{|c|}{ Mesophilic } & \multicolumn{3}{|c|}{ Thermophilic } \\
\hline & $1.0 \mathrm{vvm}$ & $0.5 \mathrm{vvm}$ & $0.1 \mathrm{vmm}$ & $1.0 \mathrm{vvm}$ & $0.5 \mathrm{vvm}$ & $0.1 \mathrm{vmm}$ \\
\hline$\mu_{\max }\left(h^{-1}\right)$ & 0.34 & 0.33 & 0.31 & 0.39 & 0.37 & 0.33 \\
\hline $\begin{array}{c}\mathrm{RX}_{\mathrm{X}} \\
\text { (mg COD } \\
\text { removed/mg } \\
\text { VSS-h) }\end{array}$ & 0.52 & 0.51 & 0.41 & 0.55 & 0.52 & 0.40 \\
\hline $\begin{array}{c}\mathrm{Y} \\
\text { (mg VSS/ mg } \\
\text { COD } \\
\text { removed) }\end{array}$ & 0.66 & 0.65 & 0.75 & 0.70 & 0.72 & 0.80 \\
\hline $\mathrm{kd}_{\mathrm{d}}\left(\mathrm{d}^{-1}\right)$ & 0.0996 & 0.0999 & 0.1048 & 0.0923 & 0.0929 & 0.1001 \\
\hline $\mathrm{Ks}(\mathrm{mg} / \mathrm{L})$ & 200 & 255 & 230 & 160 & 205 & 210 \\
\hline $\begin{array}{c}\mu_{\max } / \mathrm{Y}^{*} \mathrm{~K}_{\mathrm{S}} \\
\left({ }^{*} 10^{-3} \mathrm{~L} / \mathrm{mg}-\right. \\
\mathrm{h})\end{array}$ & 2.57 & 1.99 & 1.79 & 3.48 & 2.51 & 1.96 \\
\hline
\end{tabular}

\section{Conclusions}

Temperature and aeration rate are the factors affecting the removal of organic matter in the aerobic digestion process because, at high temperature, the dissolve oxygen was limited and thus, the amount used in the decomposition of organic matter not enough. The results showed that the highest removal efficiency of the aerobic sludge digestion was obtained at the thermophilic temperature and aeration rate of $1.0 \mathrm{vvm}$. The removal efficiency of organic matter in terms of COD, total solids (TS) and volatile solids (VS) were $35 \%, 33 \%$ and $43 \%$, respectively. As the result, the highest specific growth rate of microorganisms was 0.39 per hour and the substrate removal rate was 0.55 milligram COD removed per milligram VSS per hour. The maximum specific growth rate $\left(\mu_{\max }\right)$ of microorganisms in the aeration rate of 1.0 and $0.5 \mathrm{vvm}$ was higher than that of the aeration rate of $0.1 \mathrm{vvm}$, and the rate of removal substrate was in the same pattern. In addition, the thermophilic temperature condition provided the faster rate decomposition of organic matter than the mesophilic one. The amount of the thermophilic organic matter was less than the mesophilic condition. Furthermore, the slowly biodegradable organic matter was hydrolyzed to the readily biodegradable organic matter and inert soluble organic matter. Finally, the sludge effluent from the aerobic sludge digestion fed to the anaerobic sludge digestion resulted in the improvement of the removal efficiency of organic matter in terms of COD, TS and VS 
by having increased $25 \%, 17 \%$ and $28 \%$, respectively. Moreover, the methane production rate in the anaerobic sludge digestion was obtained approximate $0.234 \mathrm{~m}^{3} / \mathrm{kg}$ COD removed.

This work was supported by National Research Council of Thailand and Suranaree University of Technology and Thailand Institute of Scientific. We would like to thank the staff for their continual assistance in preparing and carrying out this research in the Institute of Environmental Engineering, Suranaree University of Technology.

\section{References}

1. R. U. Rani, S. A. Kumar, S. Kaliappan, I. T.Yeom, J. R. Banu, Bioresource Technology, 103, 415-424, (2012)

2. C.-N. Chang, Y.-S. Ma, and C.-W. Lo, Chemical Engineering Journal. 90, 273-281. (2002)

3. S.J. Arceivala, S.R. Asolekar, Wastewater Treatment for Pollution Control and Reuse (Tata McGraw-Hill, New Dehli, India, 2007)

4. T.B. El-hadj, D.R. Marquez-Serrano, J. MataAlvarez, Wat. Res. 41, 87-94, (2007)

5. Metcalf and Eddy, Wastewater Engineering: Treatment and Reuse (McGraw-Hill Inc., Singapore, 2004)

6. S. Bernard, N.F. Gray, Wat. Res. 34(3), 725-734, (2000)

7. I.A. Nges, J. Liu, Renewable Energy 34, 1795-1800, (2009)
8. G.D. Zupancic, M. Ros, Biores. Technol. 99, 100109, (2008)

9. M.A. Rubia, M. Perez, L.I. Romero, D. Sales, Process Biochem. 41, 79-86, (2006)

10. Y. C. Song, S.J. Kwon, J. H. Woo, Wat. Res. 38, 1653-1662, (2004)

11. J. O. Ugwuanyi, L.M. Hervey, B. McNeil, Biores Technol. 96, 707-719, (2005)

12. J. O. Ugwuanyi, L.M. Hervey, B. McNeil, Biores. Technol. 96, 721-730, (2005)

13. G. A. Ekama, P.L. Dold, G.V.R. Marais, Water Sci. Technol. 18, 91-114, (1986)

14. X. Wang, Z. Qiu, S. Lu, W. Ying, J. Hazard. Mater. $176,35-40,(2010)$

15. M. C. Wentzel, A. Mbewe, M. T. Lakay, G. A. Ekama, Water SA 25(3), 327-336, (1999)

16. C. Dumas, S. Perez, E. Paul, X. Lefebvre, Biores. Technol. 101(8), 2629-2636, (2010)

17. D. C. Bolzonella, F. Cavinato, P. Pavan, F. Cecchi, Waste Management. 32, 1196-1201, (2012) 